\title{
Erratum
}

\section{Expression of Concern: Wang et al., "Reducing Amyloid-Related Alzheimer's Disease Pathogenesis by a Small Molecule Targeting Filamin A"}

JNeurosci is publishing an Expression of Concern for the article, “Reducing Amyloid-Related Alzheimer's Disease Pathogenesis by a Small Molecule Targeting Filamin A," by Hoau-Yan Wang, Kalindi Bakshi, Maya Frankfurt, Andres Stucky, Marissa Goberdhan, Sanket M. Shah, and Lindsay H. Burns, which appeared on pages 9773-9784 of the July 18, 2012 issue. The editors have been made aware of concerns about Western blots in this study, including those published with the article's erratum (Wang et al., 2021). These and other concerns are currently under investigation by the academic authorities at the City University of New York (CUNY). JNeurosci will await the outcome of that investigation before taking further action.

\section{Reference}

Wang H-Y, Bakshi K, Frankfurt M, Stucky A, Goberdhan M, Shah SM, Burns LH (2021) Erratum: Wang et al., Reducing amyloid-related Alzheimer's disease pathogenesis by a small molecule targeting filamin A. J Neurosci. Advance online publication. Retrieved November 24, 2021. doi:10.1523/jneurosci.215421.2021

DOI: $10.1523 /$ JNEUROSCI.2306-21.2021 